quinine, severe hypoglycaemia was not detected (p 1169) (Hall and Bhattacharya, unpublished).

Quinidine has long been recognised to be at least as good a blood schizonticide as quinine. Recent studies in Thailand have shown both that this drug (the D-enantiomer of quinine) is severalfold more active than quinine against $P$ falciparum in vitro and that it may replace it for the treatment of uncomplicated infections (P Suntharasamai, S Vanijanond, $\mathrm{T}$ Harinasuta, et al, paper presented at 11 th international congress of tropical medicine and malaria, Calgary, Canada, 1984). ${ }^{10}$ The theoretical objection to quinidine is that it causes a greater prolongation of the Q-T interval than quinine, " but it may be used to treat severe falciparum malaria. ${ }^{12}{ }^{13}$ Again in Thailand, White and his team recommended a loading dose of quinidine of $15 \mathrm{mg}$ base $/ \mathrm{kg}$ followed by $7.5 \mathrm{mg}$ base $/ \mathrm{kg}$ every eight hours. ${ }^{13}$ They have not, however, done a controlled study of intravenous quinine and intravenous quinidine. Quinine in the non-toxic doses used should normally be given for severe falciparum infections from areas other than Thailand $(\mathrm{p} \mathrm{1169})^{2}$ (Hall and Bhattacharya, unpublished). Quinidine in equivalent doses should be used if quinine is not available in the hospital pharmacy. Preliminary reports suggest that an even more rapid schizonticidal response may follow the infusion of artesunate, a soluble derivative of the Chinese compound artemisinin. ${ }^{14}$ There were 960 patients with falciparum malaria from Africa treated in Britain between 1983 and 1984 but only one patient from Thailand (Malaria Reference Laboratory reports).

Supportive management of the life threatening complications of severe falciparum malaria include the reduction of hyperpyrexia, control of convulsions if present, exchange blood transfusion mentioned above, haemodialysis for anuric renal failure, and endotracheal intubation with intermittent positive pressure respiration for acute pulmonary oedema or severe coma (A P Hall, unpublished). Corticosteroids are now agreed to be contraindicated in the management of falciparum malaria. ${ }^{5}$ The careful maintenance of fluid balance is of vital importance, since fluid overload may precipitate acute pulmonary oedema with its serious prognosis. $^{2}$

Malaria caused by some strains of $P$ falciparum acquired in areas where chloroquine resistance is prevalent, and especially in South East Asia, ${ }^{3}$ may recrudesce after initial response to quinine or, less often, to quinidine. ${ }^{10}$ This problem may be avoided by concluding treatment with either a single dose of the pyrimethamine-sulfadoxine combination Fansidar in countries where this remains effective $\mathrm{e}^{\mathrm{ls}}$ (Hall and Bhattacharya, unpublished) or a five to seven day course of tetracycline if resistance to this combination is present. ${ }^{16}$

Joint Director,
Public Health Laboratory Service Malaria Reference Centre,

W PETERS

London School of Hygiene and Tropical Medicine,

London WCIE 7HT

Consultant Physician,

A P HaLL

Hospital for Tropical Diseases,

London NW1 OPE

1 Gyr K, Speck B, Ritz R, Cornu P, Buckner CD. Zerebrale malaria tropical mit schwarzwasserfieber. Schweiz Med Wochenschr 1974;104:1628-30.

2 Hall AP. The treatment of severe falciparum malaria. Trans R Soc Trop Med Hyg 1977;71:367-79.

3 Chongsuphajaisiddhi T, Sabcharoen A, Attanath P. In vivo and in vitro sensitivity of falciparum malaria to quinine in Thai children. Ann Trop Paediatr 1981;1:21-6.

4 White NJ, Looareesuwan S, Warrell DA, et al. Quinine loading dose in cerebral malaria. Am $\mathcal{J}$ Trop Med Hyg 1983;32:1-5.

5 Warrell DA, Looareesuwan S, Warrell MJ, et al. Dexamethasone proves deleterious in cerebral malaria. A double blind trial in 100 comatose patients. N Englf Med 1982;306:313-9.
6 White NJ, Warrell DA, Chantavanich P, et al. Severe hypoglycemia and hyperinsulinemia in falciparum malaria. N Englf Med 1983;309:61-6.

7 White NJ, Warrell DA, Looareesuwan S, Chanthavanich P, Phillips RE, Pongpaew P. Pathophysiological and prognostic significance of cerebrospinal-fluid lactate in cerebral malaria. Lancet 1985; ; :776-8.

8 White NJ, Warrell DA, Looareesuwan S, et al. Hypoglycaemia in falciparum malaria. $Q \mathcal{J}$ Med 1982;51:508-9.

White NJ, Warrell DA. Clinical management of chloroquine-resistant Plasmodium falciparum malaria in Southeast Asia. Trop Doct 1983;13:153-8.

10 White NJ, Logresuwan S, Warrell DA, Chongsuphajaisiddhi T, Bunnag D, Harinasuta T. Quinidine in falciparum malaria. Lancet 1981 ;ii: 1069-71.

11 White NJ, Looareesuwan S, Warrell DA. Quinine and quinidine: a comparison of EKG effects during the treatment of malaria. $f$ Cardiovasc Pharmacol 1983;5:173-5.

12 Ris HB, Stahel E, Pittet JF, Friedmann M. Das Antiarrhythmikum Chinidin als Alternative in der Behandlung der schweren Falciparum-Malaria. Schweiz Med Wochenschr 1983;113:254-8.

13 Phillips RE, Warrell DA, White NJ, Looareesuwan S, Karbwang J. Intravenous quinidine for the treatment of severe falciparum malaria. Clinical and pharmacokinetic studies. $N$ Engl f Med 1985;312:1273-8

$14 \mathrm{Li} \mathrm{G}$, Arnold K, Guo X, Jian H, Fu L. Randomised comparative study of mefloquine, qinghaosu, and pyrimethamine-sulfadoxine in patients with falciparum malaria. Lancet 1984;ii: 1360-1.

15 Hall AP, Doberstyn EB, Mettaprakong V, Sonkom P. Falciparum malaria cured by quinine followed by sulfadoxine-pyrimethamine. Br Med f 1975;ii:15-7.

6 World Health Organisation. Advances in malaria chemotherapy. Report of a scientific group. Geneva: World Health Organisation, 1984. (WHO Tech Rep Ser, No 711.)

\section{Blood lead and blood pressure}

Exposure to lead and its possible effect on health has long been a topic of public and scientific concern. Much of this concern has focused on the contribution of leaded petrol to the total body content of lead and the possibility that moderate rises in body lead may affect the mental development of children. ${ }^{12}$ Concern has also been expressed about the link between exposure to lead and hypertension, even though no consistent relation has been shown in those who have been exposed to high concentrations of lead in an industrial setting. ${ }^{3}$ The hypothesis that hypertension may be causally related to raised blood lead concentrations has been supported by the fact that the solubility of lead is increased in soft, acidic water, that in areas where the water supply is soft the mortality rate from cardiovascular disease is increased, and that hypertension is a major contributor to cardiovascular mortality.

Glasgow was the centre for much of the early work on this subject, for the drinking water is extremely soft, lead plumbing systems are common, and there is a high prevalence of hypertension and a very high cardiovascular mortality rate. In 1972, in the suburb of Renfrew, 3001 men and women residents aged 45-64 were screened for hypertension (diastolic blood pressure greater than $100 \mathrm{~mm} \mathrm{Hg}$ ). ${ }^{4}$ Hypertension was present in 468 and the first 135 who attended a follow up clinic were matched for age and sex with 135 normotensive people randomly selected from the same population. Mean blood lead concentrations were higher in the hypertensive group, in whom concentrations greater than $2 \mu \mathrm{mol} / 1(41 \mu \mathrm{g} / 100 \mathrm{ml})$ occurred more frequently. In a paired analysis of hypertensive and normotensive men $(n=74)$, using three categories of blood lead concentration, there were more pairs in which the hypertensive man had a higher blood lead concentration. A similar analysis for women gave results that were not statistically significant. The authors concluded that high blood pressure in the west of Scotland "is associated with high blood lead levels, which might explain the high prevalence of cardiovascular disease in the area." When this study was carried out the important influences of alcohol and smoking on blood lead were not known, ${ }^{5}$ nor was there an awareness of the effects of alcohol on blood pressure. ${ }^{6}$ Thus it is possible that the higher blood lead concentrations in the hypertensive subjects were due to 
higher intakes of alcohol and to the smoking that commonly accompanies drinking. Furthermore, the control group might have differed in some other way-for example, in social class or area of Renfrew - and that may have influenced blood lead concentrations. But despite these possible drawbacks the Renfrew study is still quoted widely in support of the positive relation between blood lead concentration and hypertension.

A larger study of blood lead and blood pressure has been undertaken as part of the British Regional Heart Study. This is a prospective study of cardiovascular disease in Britain that aims to explain the regional variations in cardiovascular mortality and to identify the environmental and personal risk factors responsible for ischaemic heart disease. ${ }^{7}$ The study has shown striking differences in mean blood pressure between groups of men in 24 towns in England, Wales, and Scotland. These were due partly to differences in body mass index and alcohol intake, but these two factors explain only a small part of the between town variation in blood pressure. Soft water supplies are related to cardiovascular mortality rates, and towns with soft water have the highest concentrations of lead both in the water supply and in the blood of the inhabitants. ${ }^{8}$ So, could the body lead burden (reflected in blood lead concentrations) be contributing to cardiovascular mortality, either by raising blood pressure or by some other effect on ischaemic heart disease?

Blood lead concentration and blood pressure were measured in $95 \%$ of 7735 middle aged men drawn at random from general practices in the 24 towns. No positive association between blood lead concentration and blood pressure was found, although among those men with blood concentrations greater than $1.8 \mu \mathrm{mol} / 1(37 \cdot 3 \mu \mathrm{g} / 100 \mathrm{ml})$ there were more hypertensive subjects than in those with lower concentrations. ${ }^{9}$ Nevertheless, since this group accounted for less than $1 \%$ of the men in the study it seems unlikely that exposure to lead has an appreciable effect on blood pressure in the male population of Great Britain. These findings contrast with those reported by French workers, who studied 431 men aged 24-55 years and found a positive association between blood lead concentration and blood pressure. ${ }^{10}$ The association was statistically significant for men aged under 45 but not for those aged 45-55. The authors suggest that "the increase in blood lead concentration parallels the increase in blood pressure until some limit value so that such a trend is apparent only when other factors (such as age) do not competitively increase blood pressure by greater amounts."

More substantial evidence of a positive association between blood lead and blood pressure comes from the United States. The second United States National Health and Nutrition Examination Survey examined 20322 people aged 6 months to 74 years recruited from 64 different areas across the United States. For both black and white men and women aged 12-74, blood lead concentrations were positively associated with systolic and diastolic blood pressures. "In the younger age group (21-55 years) blood lead concentrations were significantly higher in hypertensive than in normotensive subjects but this was not the case in those aged 56-74. Some 34 other variables were also identified as having a statistically significant univariate correlation with blood pressure. Blood lead had a statistically significant relation with systolic and diastolic blood pressure in men, the magnitude of this association being about one sixth of that observed between body mass index and blood pressure. Blood lead was not independently related to blood pressure in women. Surprisingly, no alcohol effect on blood pressure was observed for men in this study, although in women alcohol intake was independently associated with diastolic blood pressure.

The authors state that "no causal inferences should be drawn from this cross sectional survey about the blood pressure effects of lead." Nevertheless, in a second publication, focusing on the results of a subgroup of 564 white men aged 40-59 years, the conclusions were less guarded. ${ }^{12}$ The reason for selecting out this subgroup was to enable data from the United States Pooling Project and the Framingham study to be used in estimating the effects of lead on stroke, ischaemic heart disease, and all causes of mortality. Using a complex multiple regression model which included adjustments for age, body mass index, and a large number of biochemical and nutritional measurements, a significant independent relation was shown between blood lead and both systolic and diastolic blood pressure. It needs to be emphasised, however, that values of haemoglobin, serum albumin, dietary vitamin $\mathrm{C}$, potassium, riboflavin, and oleic acid were also all independently related to either systolic or diastolic blood pressure or both, and at a statistical significance equal to or greater than that achieved by blood lead. Clearly this gives cause for thought, for presumably this paper could have been written to focus on any one of these variables.

The authors hypothesised that if lead is causally related to blood pressure, changes in blood lead concentrations will produce substantial changes in blood pressure and affect the incidence of cardiovascular events. Using the data from the pooling project and the Framingham study they calculated the "effects" of lowering blood lead concentrations on fatal and non-fatal myocardial infarction and stroke and on deaths from all causes. As the second United States National Health and Nutrition Examination Survey showed a decrease of $37 \%$ in mean blood lead concentrations during 1976-80 (from 0.81 to $0.57 \mu \mathrm{mol} / \mathrm{l} ; 16.8$ to $11.8 \mu \mathrm{g} / 100 \mathrm{ml}$ ) they estimated that hypertension would decrease by $17 \cdot 5 \%$, myocardial infarction by $4 \cdot 7 \%$, stroke by $6 \cdot 7 \%$, and deaths from all causes by $5 \cdot 5 \%$.

The implication of their calculations is that a reduction in environmental lead-derived mainly from car exhaust fumes -would save large numbers of lives as well as reducing the number of non-fatal strokes and myocardial infarctions. Such extrapolations, however, seem simplistic. The determinants of hypertension are complex, and the factors concerned in the development of atherosclerosis and ischaemic heart disease equally so. Thus to leap from an inconsistent relation between blood lead and blood pressure to an immediate effect of blood lead on cardiovascular mortality seems precipitate.

Furthermore, a subsequent reanalysis of the same second United States National Health and Nutrition Examination Survey data on white men aged 46-65 by another group of investigators has come to a totally different conclusion (P G Gartside, letter submitted for publication). Their approach was to confine the multiple regression to a more limited set of variables which had already been identified as probable risk factors for hypertension, plus a few others that had previously been found to be useful. The final multiple regression analysis of 621 observations for diastolic blood pressure yielded significant associations for body mass index, coffee consumption, date of examination, and height but not for blood lead concentration $(p=0 \cdot 27)$. Similarly, systolic blood pressure was significantly related to body mass index, age, and coffee consumption but not to blood lead $(p=0 \cdot 18)$. This curious influence of coffee consumption on the relation between lead and blood pressure needs further clarification, 
since coffee is not widely regarded to be a risk factor for hypertension. (There is the current interest in the effect of coffee on blood lipids, ${ }^{13}$ as well as hypotheses relating lipid metabolism to blood pressure, ${ }^{14}$ but it seems premature to attempt a reconciliation of these various themes.)

In conclusion, the main evidence regarding lead and blood pressure comes from two large cross sectional surveys: the second United States National Health and Nutrition Examination Survey and the British Regional Heart Study. Their conflicting nindings make it impossible to make a definitive statement about the effect of environmental lead on hypertension. Further analysis of those studies may produce some rationalisation of these puzzling differences in research findings. But whatever the outcome, the issue of blood lead and hypertension is back and may remain prominent for some time.

\section{A G SHAPER}

Professor of clinical epidemiology

S J PoCOCK

Reader in medical statistics

Department of Clinical Epidemiology and General Practice,

Royal Free Hospital School of Medicine,

London NW3 2PF

1 Medical Research Council. The neuropsychological effects of lead in children: a review of recent research 1979-1983. London: MRC, 1984.

2 Pocock SJ, Ashby D. Environmental lead and children's intelligence. A review of recent epidemiological studies. The Statistician 1985;34:79-92.

3 Hunter D. The diseases of occupation. 6th ed. London: Hodder and Stoughton, 1978:276.

4 Beevers DG, Erskine E, Robertson M, et al. Blood lead and hypertension. Lancet 1976; ii: 1-3.

5 Shaper AG, Pocock SJ, Walker M, et al. Effects of alcohol and smoking on blood lead in middleaged British men. BrMed $\mathcal{F}$ 1982;284:299-302.

6 Beevers DG. Alcohol and hypertension. Lancet 1977;ii:114-5.

7 Shaper AG, Pocock SJ, Walker M, Cohen NM, Wale CJ, Thomson AG. British regional heart study: cardiovascular risk factors in middle-aged men in 24 towns. Br Med 7 1981;283:179-86.

8 Pocock SJ, Shaper AG, Walker M, et al. Effects of tap water lead, water hardness, alcohol, and cigarettes on blood lead concentrations. F Epidemiol Community Health 1983;37:1-7.

9 Pocock SJ, Shaper AG, Ashby D, Delves T, Whitehead TP. Blood lead concentration, blood pressure, and renal function. Br Med I 1984;289:872-4.

10 Orssaud G, Claude JR, Moreau T, Lellouch J, Juguer B, Festy B. Blood lead concentration and blood pressure. Br Med J 1985;290:244.

11 Harlan WR, Landis R, Schmouder RL, Goldstein NG, Harlan LC. Blood lead and blood pressure. fAMA 1985;253:530-4.

12 Pirkle JL, Schwartz J, Landis JR, Harland WR. The relationship between blood lead levels and blood pressure and its cardiovascular risk implications. Am f Epidemiol 1985;121:246-58.

13 Forde $\mathrm{OH}$, Knussen SF, Arnesen E, Thelle DS. The Tromso heart study. Coffee consumption and serum lipid concentrations in men with hypercholesterolaemia: a randomised intervention study. Br Med f 1985;290:893-5.

14 Smith-Barbaro PA. Dietary fat and blood pressure. Ann Intern Med 1983;98:828-31.

\section{Crohn's disease in the elderly}

"Your old men shall dream dreams and your young men shall see visions" said the prophet Joel, recognising that age changes us and modifies our response to important events.' In a medical context age may affect the incidence and the type of disease and its course, morbidity, and mortality. As the elderly population increases and the incidence of Crohn's disease rises the pattern of the disease in old people warrants examination. The few publications on the topic make a recent study from the gastrointestinal unit at Birmingham General Hospital of particular interest. ${ }^{2}$ Previous studies have tended to be selective and restricted either to patients treated surgically or to those with a particular distribution of disease. ${ }^{34}$

Crohn's disease in the elderly is rare. The Birmingham group had identified only 47 patients over the past 40 years who were aged over 60 at the time of diagnosis; they accounted for $8 \%$ of the total of over 600 patients, a proportion similar to that found by Goligher in his 500 patients. ${ }^{5}$ Epidemiological surveys based on defined populations rather than clinical series show that the peak incidence occurs in the third decade, after which there is a sharp fall which then tails off more gradually after 40 years of age to smaller figures in the elderly ${ }^{6.9}$ Some series have reported a second peak in the eighth decade, but with small numbers the finding may be spurious. ${ }^{9}$

Whether the extent and distribution of disease are different in the elderly has been disputed. In the Birmingham series distal ileal disease with or without spread to the right colon was the most common form, accounting for half of the cases; this is true for all age groups. Distal colonic disease, however, was more common than in younger patients and accounted for $40 \%$ compared with only $6 \%$ in younger patients. Extensive colonic or small bowel disease was uncommon. This relatively high proportion of colonic disease has been recognised in epidemiological surveys, ${ }^{79}$ and in Kyle's series from north east Scotland was most prominent in elderly women. ${ }^{6}$

The course of the disease was found to depend largely on the site of the lesion. Most of those with distal ileal disease needed laparotomy for obstruction, peritonitis, or to exclude carcinoma, but thereafter the prognosis was good. Fourteen of 22 patients with this disease distribution remained well. By contrast, patients with colonic disease rarely required surgery and were managed medically; there were only five resections in this group, and 14 of these 22 patients were also fit and well. This compares with the recently reported experience from St Mark's Hospital, where patients with colonic Crohn's disease had an accumulated probability of having bowel surgery of nearly $40 \%$ at 10 years. ${ }^{10}$ One further difference was that recurrence after the initial resection-a feature of the disease in general and particularly in young patients-occurred rarely in the Birmingham series and none of the patients required a second operation.

The overall standardised mortality ratio in Crohn's disease is usually quoted as twice the expected value for the general population. ${ }^{811-13}$ The risk of death is, however, much greater for patients who develop the disease early in life, and in one series those diagnosed in the second decade had a mortality ratio 11 times the expected value. " Elderly patients, however, have a mortality rate the same or less than the average for all patients with Crohn's disease. This may be due partly to the prominence of colonic disease, which carries a better prognosis.

Diagnosis of Crohn's disease in the elderly may be difficult because of the high prevalence of diverticular disease $\mathrm{e}^{14}$ and carcinoma of the colon or caecum. Diverticular disease was present in more than half of the patients with colonic Crohn's disease, and lack of a confident radiological diagnosis of the caecal abnormality led to laparotomy in more than a quarter of the patients with ileocaecal disease.

Recognition of the generally favourable prognosis for Crohn's disease in elderly patients, particularly those with distal colonic disease, should be of practical value to gastroenterologists, geriatricians, and surgeons. Plainly this variant is a less aggressive form of the disease than that seen in younger patients.

JOHN RHODES Consultant physician JAMES ROSE

University Hospital of Wales, Senior registrar Cardiff CF4 4XW

\footnotetext{
1 Holy Bible. Joel ii,28.

2 Fabricius PJ, Gyde SN, Shouler P, Keighley MRB, Alexander-Williams J, Allan RN. Crohn's disease in the elderly. Gut 1985;26:461-5.

3 Rusch V, Simonowitz DA. Crohn's disease in the older patient. Surg Gynecol Obstet 1980;150: 184-6.
} 